\title{
Type II odontoid fractures: Complication, mortality, and outcome after posterior C1-C2 fixation and fusion, single institute experience
}

Gezgin Inan ( $\sim$ gezgininan@gmail.com )

Dr Ersin Aslan Training and Research Hospital

\section{Murat Gokten}

Dr. Ersin Arslan Training and Research Hospital

\section{Can Sezer}

Dr. Ersin Arslan Training and Research Hospital

\section{Aykut Sezer}

Dr. Ersin Arslan Training and Research Hospital

Abidin Murat Geyik

Dr. Ersin Arslan Training and Research Hospital

\section{Sedat Cagli}

Ege Universitesi Tip Fakultesi

\section{Research article}

Keywords: Odontoid fractures, Type II, posterior C1-C2 fixation, fusion

Posted Date: March 17th, 2020

DOI: https://doi.org/10.21203/rs.3.rs-17531/v1

License: (1) This work is licensed under a Creative Commons Attribution 4.0 International License.

Read Full License 


\section{Abstract}

Background The aim of the present study was to evaluate long term $\mathrm{C} 1-\mathrm{C} 2$ fusion rates and functional outcomes in patients with type II odontoid fractures treated with posterior fixation with polyaxial C1 lateral mass and $\mathrm{C} 2$ pars screws.

Methods A total of 32 patients were retrospectively evaluated. Study parameters included Japanese Orthopaedic Association (JOA) score and visual analog scale score for neck pain. All patients had computerized tomography (CT) scans preoperatively and at six months postoperatively; X-rays preoperatively and at three months and 12 months after operation

Results Among the etiological factors, first (59.4\%) fall from high and second (40.6\%) traffic accidents have been observed. The duration of follow-up was $28.4 \pm 8.5$ months. A total of 25 patients had improvement on mean VAS score. A total of 12 patients had improvement at modified JOA score. No vascular injury occurred in our series. One patient (3.1\%) developed hospital pneumonia, and the patient died at postoperative 6 th week. One patient (3.1\%) had nonunion, but no neurological deficit was observed, and revision surgery was not needed 30 patients $(93.8 \%)$ had fracture healing and fusion after posterior $\mathrm{C} 1-\mathrm{C} 2$ fixation.

Conclusions In our opinion, posterior $\mathrm{C} 1-\mathrm{C} 2$ fixation and fusion is the treatment of choice in type II odontoid fractures with good fusion results. We achieved good results and low complication and mortality rates.

\section{Background}

Odontoid fractures constitute approximately $18 \%$ of all cervical fractures [1]. Although the incidence of neurological damage due to odontoid fractures is considered low, approximately $25-40 \%$ of the patients are lost at the site of the event [1]. The mechanism of odontoid fractures is usually responsible for hyperflexion or hyperextension injuries of the cervical spine [2]. The classification used for odontoid fractures is defined by Grauer et al. [3]. With this classification, odontoid fractures are divided into 3 basic types of fractures: Type I fractures are avulsion fractures over the transverse ligament, and at the top of the odontoid; Type II fractures are vertebral body- odontoid junction fractures; Type III fractures describe odontoid fractures involving the anterior proximal part of the vertebral body. In order to decrease the number of debates concerning the treatment modalities inType II odontoid fractures in 2005, Gauer divided type II odontoid fractures into three subtypes as Type IIA Type IIB and Type IIC [4].

Treatment of odontoid fractures varies according to the type of fracture. Since Type I and III fractures can be treated with cervical collar applied for most 6-8 weeks or external immobilization methods such as a halo vest [5]. Type II odontoid fracture usually has lower fusion rates and is less stable compared to Type I and Type III. The treatment of these fractures is not well defined. External immobilization with cervical collar and halo results in unreliable and inconsistent results. New developments in cervical fixation methods in defining and classifying odontoid fractures cause controversies about the treatment of Type II 
odontoid fractures. Although wiring methods as $\mathrm{C} 1$ - $\mathrm{C} 2$ posterior fusion techniques are commonly used surgical methods in odontoid fractures, the rotation of the neck with this technique decreases by about $50 \%$ [6]. For posterior C1 - C2 fusion techniques, wiring methods, posterior stabilization using screws applied into posterior $\mathrm{C} 1$ isthmus, and posterior fixation with polyaxial $\mathrm{C} 1$ lateral mass and $\mathrm{C} 2$ pars screws as described by Harms and Melcher can be used [7].

This study aims to evaluate long term $\mathrm{C} 1-\mathrm{C} 2$ fusion rates and functional outcomes in patients with high velocity type II odontoid fractures treated with posterior fixation with polyaxial C1 lateral mass and C2 pars screws.

\section{Methods}

\section{Study Design:}

The study has been conducted by the principles of the Helsinki Declaration and approved by the local Institutional Review Board. The need for consent was waived by the institutional IRB as the study was retrospective. A total of 32 patients with high velocity type II odontoid fractures treated by C1-C2 posterior fixation and fusion with Harm's technique between 2010 and 2017 were retrospectively evaluated.

Low velocity fractures such as elderly standing level fall odontoid fractures were excluded from the study.

\section{Surgical Procedure:}

Computerized tomography (CT) or magnetic resonance (MR) angiography was performed in all cases to predict which patients can safely undergo placement of a transarticular screw. All patients received awake fiberoptic intubation, and the surgical position was prone, taking care to avoid excessive pressure on the eyes. The incisions were at midline. Infiltration of the skin and subcutaneous tissue with a dilute 1:500000 epinephrine solution was helpful to provide hemostasis. Using electrocautery and elevators, we exposed the posterior elements subperiosteally and inserted self-retaining retractors. The inferior surface of the posterior arch of $\mathrm{C} 1$ was exposed towards the lateral edges. $\mathrm{C} 1$ articular mass screw insertion requires the direct posterior visualization of $\mathrm{C} 1-\mathrm{C} 2$ articular joint. Once the $\mathrm{C} 1-\mathrm{C} 2$ joint margins were defined by two Freers or Penfields placed on either side, a unicortical starting hole was created on the inferior border of $\mathrm{C} 1$ posterior arch using a high speed burr. With the aid of the two dissectors as a guide, drill was then directed anteriorly within the $\mathrm{C} 1$ lateral mass. Bicortical screw placement could be performed under fluoroscopic guidance with caution, although overall this was reasonably safe as there is some safety margin anteriorly prior to important structures. The screw preferred was partially threaded, to avoid irritation of the $\mathrm{C} 2$ root. Careful exposure of the postero-medial border of the $\mathrm{C} 2$ pedicle facilitated the drilling and screw placement by the direct visualization of the pedicle. The drilling could be performed safely and start from the lateral part of the articular mass of $\mathrm{C} 2$. The pedicle diameter should be measured preoperatively on the CT scan images and the screw diameter was $0.5 \mathrm{~mm}$ less than the pedicle. Postoperatively, all patients were followed with Philadelphia collar for 12 weeks. 


\section{Outcome Parameters:}

All fractures were classified according to Grauer classification system [3].

Study parameters included pre- and postoperative neurologic status evaluated by Japanese Orthopaedic Association (JOA) score and visual analog scale score for neck pain [8].

All patients had CT scans preoperatively and at six months postoperatively; $X$-rays preoperatively and at three months and 12 months after operation (Fig. 1, 2).

\section{Results}

Thirty-two patients met the eligibility criteria for the study. Of the 32 patients ( 14 males, 18 females) whose charts were reviewed, the mean age was $50.14 \pm 13.12$ (range, 28 to 78 ) years. The duration of follow-up was $28.4 \pm 8.5$ months. Among the etiological factors, first $(59.4 \%)$ fall from high and second $(40.6 \%)$ traffic accidents have been observed (Table 1 ). 
Table 1

General characteristics of patients.

\begin{tabular}{|c|c|c|c|c|c|c|c|c|c|}
\hline & Sex & $\begin{array}{l}\text { Injury } \\
\text { Type }\end{array}$ & $\begin{array}{l}\text { Preop } \\
\text { JOA }\end{array}$ & $\begin{array}{l}\text { Postop } \\
\text { JOA }\end{array}$ & $\begin{array}{l}\text { Preop } \\
\text { VAS }\end{array}$ & $\begin{array}{l}\text { Postop } \\
\text { VAS }\end{array}$ & $\begin{array}{l}\text { 6th mo } \\
\text { fusion }\end{array}$ & $\begin{array}{l}\text { 12th mo } \\
\text { fusion }\end{array}$ & FU \\
\hline 1 & $\mathrm{M}$ & Accident & 9 & 14 & 4 & 3 & + & + & 36 \\
\hline 2 & $\mathrm{~F}$ & Fall & 15 & 15 & 5 & 2 & - & + & 14 \\
\hline 3 & $\mathrm{M}$ & Fall & 18 & 18 & 7 & 2 & + & + & 42 \\
\hline 4 & $F$ & Accident & 9 & 13 & 6 & 3 & + & + & 28 \\
\hline 5 & $F$ & Fall & 17 & 18 & 3 & 5 & - & + & 21 \\
\hline 6 & $F$ & Fall & 18 & 18 & 4 & 0 & + & + & 31 \\
\hline 7 & $\mathrm{M}$ & Accident & 16 & 12 & 5 & 1 & + & + & 35 \\
\hline 8 & $\mathrm{M}$ & Fall & 17 & 13 & 8 & 5 & - & + & 39 \\
\hline 9 & $\mathrm{~F}$ & Fall & 16 & 16 & 5 & 2 & + & + & 41 \\
\hline 10 & M & Fall & 18 & 18 & 4 & 1 & + & + & 42 \\
\hline 11 & $\mathrm{~F}$ & Accident & 18 & 18 & 5 & 8 & - & + & 27 \\
\hline 12 & $M$ & Fall & 18 & 18 & 4 & 2 & + & + & 25 \\
\hline 13 & M & Fall & 16 & 16 & 4 & 1 & + & + & 31 \\
\hline 14 & $F$ & Fall & 12 & 15 & 8 & 3 & + & + & 23 \\
\hline 15 & $\mathrm{M}$ & Accident & 18 & 18 & 3 & 3 & + & + & 26 \\
\hline 16 & $F$ & Fall & 18 & 13 & 5 & 2 & + & + & 24 \\
\hline 17 & $F$ & Fall & 18 & 12 & 4 & 8 & - & - & 2 \\
\hline 18 & $F$ & Fall & 16 & 16 & 3 & 1 & + & + & 29 \\
\hline 19 & $\mathrm{M}$ & Fall & 14 & 16 & 3 & 1 & + & + & 25 \\
\hline 20 & $F$ & Accident & 18 & 18 & 4 & 1 & + & + & 22 \\
\hline 21 & $F$ & Accident & 18 & 18 & 5 & 2 & + & + & 24 \\
\hline 22 & M & Accident & 18 & 18 & 4 & 3 & + & + & 27 \\
\hline 23 & $M$ & Fall & 18 & 18 & 4 & 2 & - & + & 27 \\
\hline 24 & $F$ & Accident & 14 & 17 & 5 & 2 & + & + & 33 \\
\hline
\end{tabular}

FU: Follow up; F: Female; M: Male; JOA: Japanese Orthopedic Association; VAS: visual analog scale. 


\begin{tabular}{|llllllllll|}
\hline Sex & $\begin{array}{l}\text { Injury } \\
\text { Type }\end{array}$ & $\begin{array}{l}\text { Preop } \\
\text { JOA }\end{array}$ & $\begin{array}{l}\text { Postop } \\
\text { JOA }\end{array}$ & $\begin{array}{l}\text { Preop } \\
\text { VAS }\end{array}$ & $\begin{array}{l}\text { Postop } \\
\text { VAS }\end{array}$ & $\begin{array}{l}\text { 6th mo } \\
\text { fusion }\end{array}$ & $\begin{array}{l}\text { 12th mo } \\
\text { fusion }\end{array}$ & FU \\
\hline 25 & F & Fall & 18 & 18 & 6 & 2 & + & + & 36 \\
\hline 26 & M & Fall & 18 & 18 & 7 & 1 & + & + & 32 \\
\hline 27 & F & Fall & 18 & 18 & 8 & 3 & + & + & 34 \\
\hline 28 & M & Accident & 8 & 8 & 7 & 2 & + & + & 33 \\
\hline 29 & F & Accident & 9 & 13 & 6 & 2 & - & + & 38 \\
\hline 30 & F & Fall & 9 & 9 & 6 & 3 & - & - & 18 \\
\hline 31 & M & Accident & 5 & 11 & 5 & 2 & + & + & 22 \\
\hline 32 & F & Accident & 15 & 13 & 6 & 1 & + & + & 23 \\
\hline FU: Follow up; F: Female; M: Male; JOA: Japanese Orthopedic Association; VAS: visual analog scale. \\
\hline
\end{tabular}

VAS score for neck pain was $5.09 \pm 1.48$ preoperatively, and $2.75 \pm 1.77$ postoperatively. A total of 25 patients had improvement on mean VAS score, and three patients had the same VAS score, and three patients had worsened VAS score in the postoperative period.

Modified JOA score was $15.2 \pm 3.8$ (range, 5 to 18 ) preoperatively, and $15.5 \pm 2.90$ at 12 months postoperatively. A total of 12 patients had improvement at modified JOA score, and four patients had worsened modified JOA score in the postoperative period. The mean JOA score was $13.4 \pm 4.77$ in patients with a traffic accident in etiology, and this value was $16.4 \pm 2.45$ in patients with a fall from a height $(p>0.05)$.

No vascular injury occurred in our series. One patient (3.1\%) had surgical wound infection, one patient (3.1\%) had surgical wound site hematoma, 1 patient (3.1\%) had pulmonary embolism, and 1 patient (3.1\%) had a cerebrovascular event, all patients were treated One patient (3.1\%) developed hospital pneumonia, and the patient died at postoperative 6th week. One patient (3.1\%) had nonunion, but no neurological deficit was observed, and revision surgery was not needed 30 patients (93.8\%) had fracture healing and fusion after posterior C1-C2 fixation.

\section{Discussion}

Odontoid fractures constitute $15-20 \%$ of all cervical spine fractures and are formed by a combination of flexion, axial loading or extension, and rotational forces. Type II fractures constitute $60 \%$ of odontoid fractures [9]. Odontoid fractures seen in young age are frequently observed in males, but there is no gender difference in the prevalence of odontoid fractures seen in old age [9]. The most common cause of odontoid fracture is trauma [10]. All of our cases presented with a history of a traffic accident or fall from height. 
Post-traumatic neck pain in odontoid fractures can often be the only complaint. Non-displaced fractures can be overlooked in direct radiography, axial CT and magnetic resonance images. the best imaging modality is CT reconstructions [10]. In the present study, all patients had preoperative CT with 3dimensional reconstruction.

It is reported that there are many factors affecting the percentage of fusion. Dunn and Seljeskog stated that posterior dislocation, being 64 years and over, and having severe neurological deficits were negative factors in the achievement of the union [11]. In a series of 45 patients, Apuzzo et al. found the rate of nonunion as $33 \%$ in patients over 40 years of age and in patients having dislocation over $4 \mathrm{~mm}$. [12]. The degree of dislocation of dens is the most frequently affecting factor in the percentage of the union in external immobilization. In their series of 107 cases, Hadley et al. reported nonunion rates as 67, and 9\% in dislocations of more and less than $6 \mathrm{~mm}$, respectively [13]. In the present study, ten patients had odontoid displacement more than $5 \mathrm{~mm}$ (mean $6.2 \mathrm{~mm}$ ), and 12 patients had posterior dens displacement.

In the present study, 96\% fusion rates were achieved by posterior C1-C2 fixation. In literature, nearly 90$100 \%$ fusion rates were achieved with lower complication and mortality rates $[14,15]$. Complication rates were similar to literature. During the application of C1 and C2 screwing techniques, many complications involving the vascular and neural anatomical structures contained in this region should be avoided. Therefore, many researchers strive to develop different techniques [16]. Abumi et al. reported that the C2 pars screwing technique was very safe and screw malposition decreased to $7 \%$ in proportion to developing technology and experience [17]. In our study, nonunion was observed in only one (3.1\%) patient, but revision surgery was not needed due to the absence of any neurological deficit. In the initial evaluation and follow-up of patients with cervical trauma, various authors evaluated the clinical and neurological recovery with different parameters such as ASIA, Frankel, JOA score or subjective satisfaction $[18,19]$. Song et al. reported a $78.3 \%$ improvement in the JAO score with the surgical treatment in patients with unstable cervical injury [20]. We used the JOA scores in our study.

In their study, Jing et al. detected their complication rate as $6.67 \%$ (2 patients). In one patient, while inserting a screw into the $\mathrm{C} 1$ lateral mass, intraoperative vertebral artery damage occurred in one patient, and screw loosening happened in the follow-up of another patient [21]. In their study, Zheng et al.reported venous plexus injury in 6 patients (7\%), C2 root injury in 4 patients (4.7\%), urinary tract infection in 1 patient and wound infection in 1 patient [22]. Kizmazoglu et al. reported peroperative dura mater damage in 2 (18.2\%), postoperative wound discharge in 4 patients (36.4\%), while one patient died due to postoperative cardiac arrest [23]. In our study, surgical wound infection, hematoma, pulmonary embolism, and cerebrovascular events developed in individual patients and treatment was provided for all patients. One patient developed nosocomial pneumonia, and the patient died at postoperative sixth week.

Although the VAS is an incomplete representation of the pain experience and cannot fully reflect the multidimensional aspects of pain, it remains the most widely used metrics of pain after surgery. However, 
VAS would not always reflect the sense of pain. That may be the reason of which three patients had worse VAS scores at final follow up compared the pre-surgery VAS score.

The main limitations of the present study were the retrospective design and the relatively small size of our series. Also, some details of history and factors that may influence the outcome may not be completely documented. Finally, surgeries were performed by different surgeons. Due to these restrictions, associations should be interpreted with caution.

\section{Conclusions}

In our opinion, posterior C1-C2 fixation and fusion is the treatment of choice in type II odontoid fractures with good fusion results. We achieved good results and low complication and mortality rates.

\section{Abbreviations}

CT

Computerized tomography

MR

Magnetic resonance

JOA

Japanese Orthopaedic Association

\section{Declarations}

Ethics approval and consent to participate: The approval of the Gaziantep University Institutional Review Board was obtained prior to the study. Necessary permission was obtained in using the hospital records of the patients. The need for consent was waived by the institutional IRB as the study was retrospective.

Consent for publication: Not applicable.

Availability of data and material: The datasets used and/or analyzed during the current study are available from the corresponding author on reasonable request.

Competing interests: The authors declare that they have no competing interests.

Funding: No financial support was received for this paper.

Authors' contributions: All authors have read and approved the manuscript. I.G. analyzed and interpreted the data, was a major contributor in writing the manuscript, read and approved the final manuscript. M.G. analyzed and interpreted the data, was a major contributor in writing the manuscript, read and approved the final manuscript. C.S. analyzed and interpreted the data, was a major contributor in writing the manuscript, read and approved the final manuscript. A.S. analyzed and interpreted the data, was a major contributor in writing the manuscript, read and approved the final manuscript. A.M.G. analyzed and 
interpreted the data, was a major contributor in writing the manuscript, read and approved the final manuscript.

Acknowledgements: Not applicable.

\section{References}

1. Rizk E, Kelleher JP, Zalatimo O, Reiter T, Harbaugh R, Mclnerney J, Sheehan J. Nonoperative management of odontoid fractures: a review of 59 cases. Clin Neurol Neurosurg. 2013;115(9):16536.

2. Maak TG, Grauer JN. The contemporary treatment of odontoid injuries. Spine. 2006;31(11):53-60.

3. Grauer JN, Shafi B, Hilibrand AS, Harrop JS, Kwon BK, Beiner JM, et al. Proposal of a modified, treatment-oriented classification of odontoid fractures. Spine J. 2005;5(2):123-9.

4. Grauer JN, Shafi B, Hilibrand AS, Harrop JS, Kwon BK, Beiner JM, et al. Proposal of a modified, treatment-oriented classification of odontoid fractures. Spine J. 2005;5(2):123-9.

5. Wang GJ, Mabie KN, Whitehill R, Stamp WG. The nonsurgical management of odontoid fractures in adults. Spine. 1984;9:229-30.

6. Schwarz F, Lawson McLean A, Waschke A, Kalff R. Cement-augmented anterior odontoid screw fixation in elderly patients with odontoid fracture. Clin Neurol Neurosurg. 2018 Dec;175:144-148.

7. Bransford RJ, Lee MJ, Reis A. Posterior fixation of the upper servical spine: Contemporary techniques. J Am Acad Orthop Surg. 2011;19:63-71.

8. Benzel EC, Lancon J, Kesterson L, Hadden T. Cervical laminectomy and dentate ligament section for cervical spondylotic myelopathy. J Spinal Disord 1991;4:286-95.

9. Vasudevan K, Grossberg JA, Spader HS, Torabi R, Oyelese AA. Age increases the risk of immediate postoperative dysphagia and pneumonia after odontoid screw fixation. Clin Neurol Neurosurg. 2014;126:185-9.

10. Fiumara E, Tumbiolo S, Lombardo MC, Maugeri R, Porcaro S, Gioia F, et al. Type II Odontoid Fracture: a case series highlighting the treatment strategies. Acta Neurochir Suppl. 2019;125:317-24.

11. Dunn ME, Seljeskog EL. Experience in the management of odontoid process injuries: An analysis of 128 cases. Neurosurg. 1986;18;306-10.

12. Apuzzo ML, Heiden JS, Weiss MH, Ackerson TT, Harvey JP, Kurze T. Acute fractures of the odontoid process. An analysis of 45 cases. J Neurosurg. 1978;48(1):85-91.

13. Hadley MN, Carol BRN, Sonntag VKH. Axis fractures. A comprehensive review of management and treatment in 107 cases. Neurosurg. 1985;17;281-90.

14. Harms J, Melcher RP. Posterior C1-C2 fusion with polyaxial screw and rod fixation. Spine. (Phila Pa 1976) 2001;26(22):2467-71.

15. Stulik J, Vyskocil T, Sebesta P, Kryl J. Atlantoaxial fixation using the polyaxial screw-rod system. Eur Spine J. 2007;16(4):479-84. 
16. Zhang HL, Zhou DS, Jiang ZS. Analysis of accuracy of computer-assisted navigation in cervical pedicle screw installation. Orthop Surg. 2011;3:52-6.

17. Abumi $K$, Shono $Y$, Ito $M$, Taneichi $H$, Kotani $Y$, Kaneda $K$. Complications of pedicle screw fixation in reconstructive surgery of the cervical spine. Spine. (Phila Pa 1976). 2000;25:962-9.

18. Krüger A, Oberkircher L, Frangen $T$, Ruchholtz $S$, Kühne $C$, Junge A. Fractures of the occipital condyle clinical spectrum and course in eight patients. J Craniovertebr Junction Spine. 2013;4(2):49-55.

19. Lenehan B, Boran S, Street J, Higgins T, McCormack D, Poynton AR. Demographics of acute admissions to a National Spinal Injuries Unit. Eur Spine J. 2009;18(7):938-42.

20. Song GC, Cho KS, Yoo DS, Huh PW, Lee BS. Surgical treatment of craniovertebral junction instability: Clinical outcomes and effectiveness in personal experience. J Korean Neurosurg Soc. 2010;48(1):3745.

21. Jing L, Sun Z, Zhang P, Wang J, Wang G. Accuracy of screw placement and clinical outcomes after O-Arm-Navigated occipitocervical fusion. World Neurosurg. 2018;117:e653-e9.

22. Zheng $\mathrm{Y}$, Hao D, Wang B, He B, Hu H, Zhang H. Clinical outcome of posterior C1-C2 pedicle screw fixation and fusion for atlantoaxial instability: A retrospective study of 86 patients. $J$ Clin Neurosci. 2016;32:47-50.

23. Kızmazoglu C, Aydin HE, Kaya I, Husemoglu RB, Kalemcı O, Ozer E. Clinical outcome of patients with individualized 3D printing assisted C1-C2 fusion. 2019. Doi: 10.20515/otd.47815

\section{Figures}
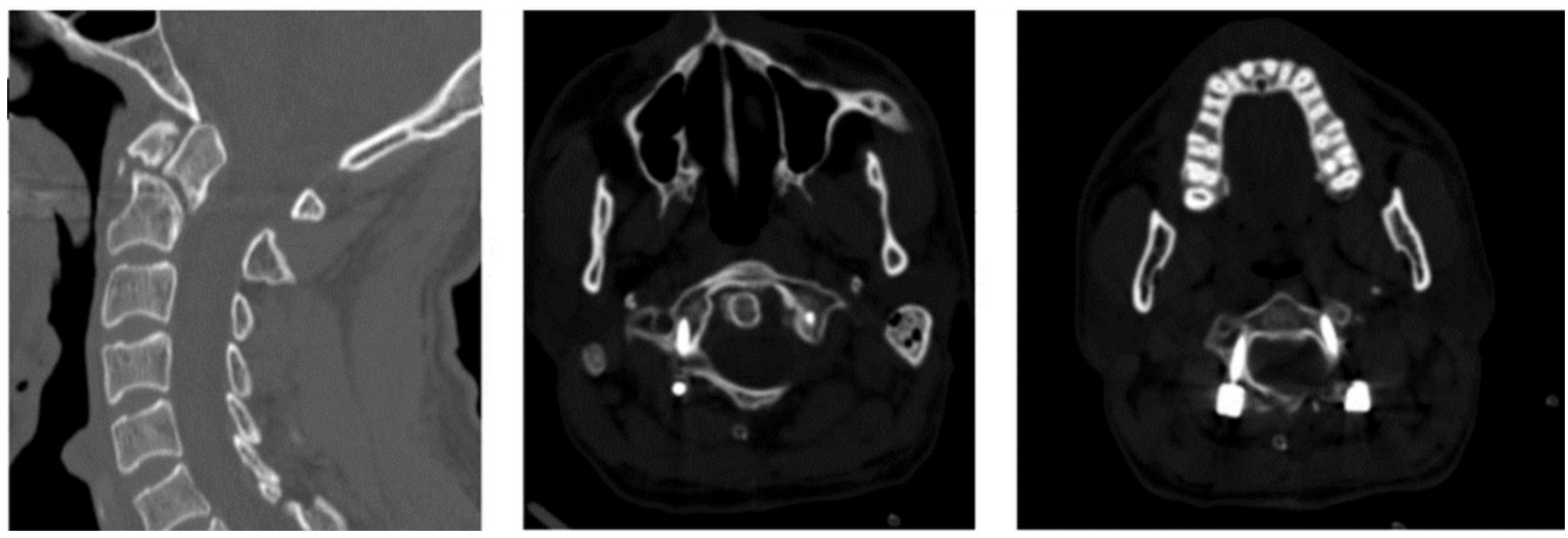

\section{Figure 1}

Type II odontoid fractures managed by $\mathrm{C} 1-\mathrm{C} 2$ posterior fixation. Computed tomography scan showing A. Fractures with posterior displacement, B. C1 lateral mass screw postoperatively, C. C2 pedicle screw. 

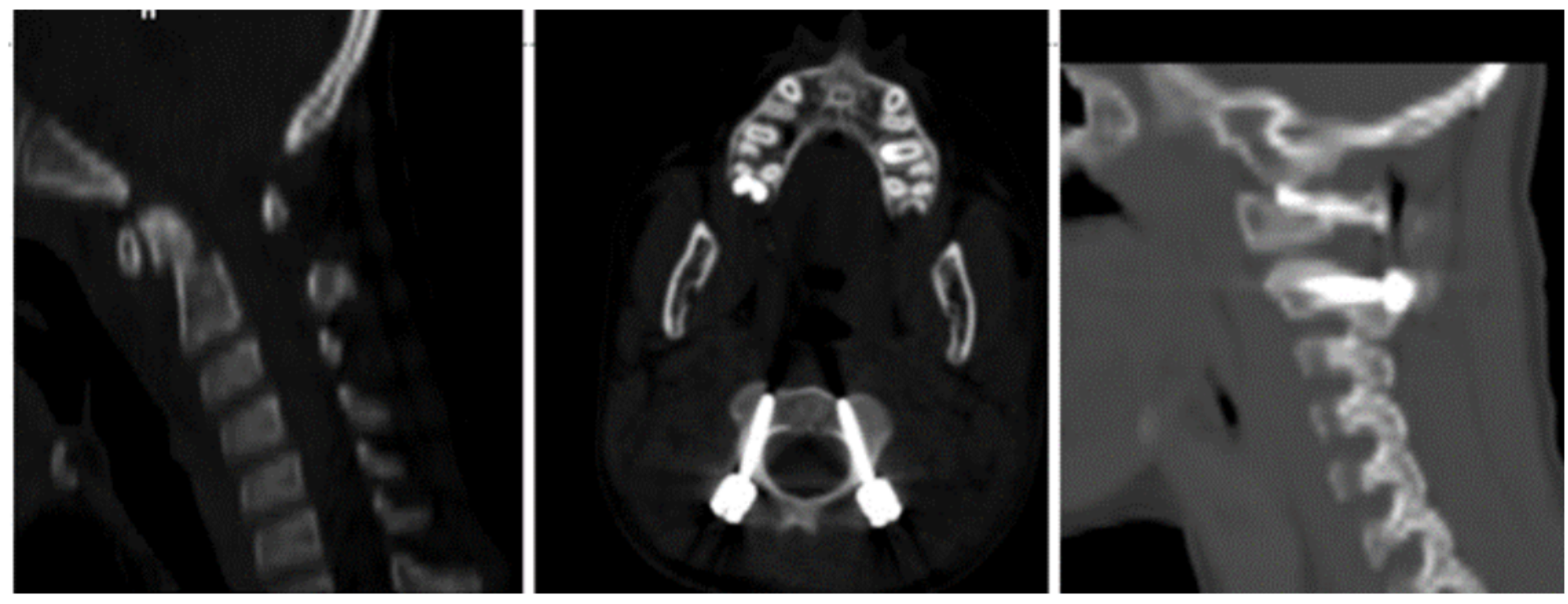

Figure 2

Computed tomography scan showing A. Anterior displacement of Type II odontoid fracture, B. C2 pedicle screw, C. C1 lateral mass and C2 pedicle screws. 